\title{
Design and Implementation of a PV powered Tri-cycle
}

\author{
SOUMYA DAS ${ }^{1}$, PRADIP K SADHU², SUPRAVA CHAKRABORTY*2, \\ SAUMEN DHARA ${ }^{3}$ and SHRAMABATI SEN ${ }^{1}$ \\ 1'Department of Electrical Engineering, University Institute of Technology, Burdwan, WB-713104, India. \\ ${ }^{2}$ Electrical Engineering Department, Indian School of Mines \\ (Under MHRD, Govt. of India), Dhanbad - 826004, India. \\ ${ }^{3}$ Department of Electrical Engineering, Saroj Mohan Institute of Technology, Guptipara, \\ Hooghly, WB -712512, India. \\ http://dx.doi.org/10.12944/CWE.11.1.11
}

(Received: February 24, 2016; Accepted: April 03, 2016)

\begin{abstract}
Solar PV technology is one of the first among the various renewable energy technologies that have been adopted and accepted universally in order to meet the basic needs of generation of electricity. The objective of this paper is to propose a tri-cycle that utilises the application of standalone photovoltaic (PV) system. A preliminary design and construction of a solar tri-cycle has been performed by evaluating and estimating the required panel size, battery capacity and motor power. Calculation in this paper exhibit that the solar power alone will be sufficient to operate a tri-cycle from one place to another.
\end{abstract}

Keywords: PV, Tri-cycle, PMDC motor, Charge Controller, DPDT switch.

\section{INTRODUCTION}

In this rapidly growing and ever evolving society, the transportation sector has been progressing heavily day by day. Consequently, more efficient vehicles need to be developed which are cleaner and faster. As the IC engine creates pollution, posing a serious threat to nature, more research is now being concentrated on renewable energy resources like solar power, wind power and biofuel etc., which are constantly and sustainably replenished. Electric vehicles or solar vehicles are emerging as a popular transport alternative, as these types of vehicles are environmentally sound, ecofriendly, cleaner and require less maintenance than gas-powered cars ${ }^{1-2}$.Significant accomplishments have been made in the last decade to gradually shift to a smarter and a greener way to lessen our reliance on conventional fuels. This has been effective partly due to the rising cost of oil as well as a gradual shift in the attitude and outlook of the drivers ${ }^{3}$. While such a vehicle is expected to have very limited range $(40$ to $50 \mathrm{~km}$ ), the possibility of being able to drive a tri-cycle to work, recharge the batteries with solar energy during the day, and drive back home at night with enough stored energy to start work the next day, offers a very attractive motive option. Research and development in the area of renewable energy is growing fast, supported by the increasing awareness about sustainability, environment and limitation of conventional sources of energy. Interestingly, oil and gas companies are realizing the potential of renewable energy, and have been supporting events and competitions that aim precisely at developing technologies and expertise for this field 4 . Beside the ever-increasing fuel price, conventional cars are also subjected to externalities cost such as cost related to environmental and health damages due to toxic emissions. These externalities are completely absent in solar tri-cycles making it more desirable to the consumers. 
The savings from the government investments on fuel powered tri-cycles can be directed towards subsidizing industries in manufacturing and encouraging public in purchasing solar tri-cycles. This will further drop the price of the solar tri-cycles, thus bringing it within the reach of the general mass. With Environmental pollution being the major cause of concern today, the use of Solar powered clean tricycle can be of great advantage to the public and the environment of the highly polluted cities all around the world. It will reduce pollution and pollution related life-threatening ${ }^{5}$.

Basically few years ago tricycle mostly used only the handicapped person. But today's life the tricycles are being widely used as the modest example of public transportation in countries like India, China, Malaysia, Vietnam, and Korea. It is also called "TOTO". These tricycles are also used for entrepreneurship for setting up some small stall or like that. This transport means stands the most widely and cheap source for such people.

This paper is about building a small tricycle that is motorized and is powered by solar energy. Solar vehicles fill a perfect niche in the urban commute car market, where the range is short and the need for nonpolluting cars is the greatest. On the other hand when the conventional energy resources i.e. the fossil fuels are at the verge of depletion, nonconventional powered vehicles are in a high demand. Among all of the nonconventional powered vehicles, solar powered vehicles are becoming popular as it is cost effective one. This paper has been much of a success to play a significant role in the modern solar car industry.

\section{EXPERIMENTAL}

There are some generic principles for designing and modeling solar tri-cycles ${ }^{6}$. The main parameters used in the selection or design of components for solar tri-cycle are the motor power, battery capacity and panel size. With this in mind, a survey of available products was carried to design the tri-cycle?

\section{Proposed system architecture}

The detailed system architecture of the complete electric drive system of the solar tri-cycle is shown in the block diagram in Fig. 1. The solar panels mounted on the roof of the tri-cycle will collect energy from the sun and convert it to usable electrical energy which will be stored in a lead acid battery through a charge controller. The charge controller will ensure healthy life of the battery by preventing over charging and over discharging of the battery. The solar tri-cycle will also have a provision of plugin charge when there is not enough sunshine due to cloud, fog or rain. This provision for external plug in to charge the batteries from the conventional power supply will also allow the tri-cycle to increase its capacity to drive for longer distance by putting additional batteries and charging from the power supply lines. The voltage controller will maintain a constant voltage at its output as is required by the motor, irrespective of the panel or the battery voltage level.

\section{Different units to design PV powered tri-cycle}

Materials used to design a typical PV powered tri-cycle are:

1. Solar panel

2. DC motor

3. Double Pole Double Trip (DPDT) switch

4. Battery, 5. Charging circuit.

To estimate the power needed to drive the tri-cycle can be calculated using (1) as:

$$
P=F \times v
$$

where $v$ is the velocity of the tri-cycle and $F$ is the force needed to overcome the frictional force between the road and the tires which can be calculated as,

$$
F=m \times g \times C_{\pi}
$$

where, $m$ is the mass of the car, $g$ is the gravitational acceleration and $C_{r}$ is the coefficient of rolling resistance of the car tires. Different tires have different $C_{r}$ depending on the type of tires, load, road type, pressure etc. Tires used for solar car are typical bicycle tires and have rolling resistance of 0.0055 on asphalt/concrete roads.

\section{Solar charging circuitry}

Here a solar charger circuit that is used to charge Lead Acid or Ni-Cd batteries using the 
solar energy power is shown. The circuit harvests solar energy to charge a 6 volt 4.5 Ah rechargeable battery for various applications. The charger has voltage and current regulation and over voltage cut-off facilities. The circuit uses a 24volt solar panel and a variable voltage regulator IC LM 317. Charging current passes through D1 to the voltage regulator IC LM 317. By adjusting its Adjust pin, output voltage and current can be regulated.Schematic of the Solar Charger circuit is shown in Fig 2 below.

Variable Resistor (VR) is placed between the Adjust pin and the ground to provide an output voltage of 9 volts to the battery. Resistor $R_{3}$ restricts the charging current and diode D2 prevents the discharge of current from the battery ${ }^{8}$. Transistor $\mathrm{T}_{1}$

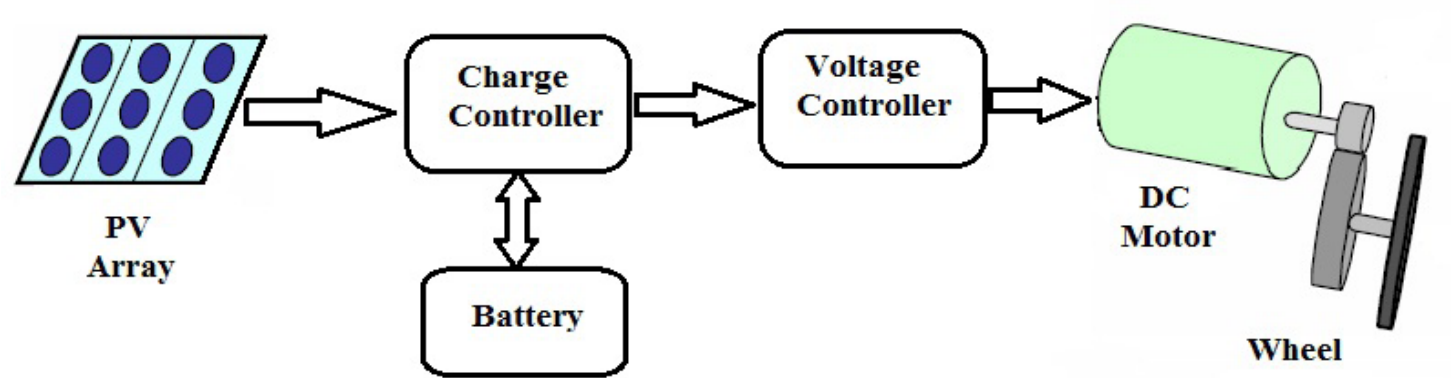

Fig. 1: Block diagram of solar tri-cycle system

Table 1: Parameter values used to design PV powered tri-cycle

\begin{tabular}{ll}
\hline PV powered tricycle & \\
Maximum speed & $10 \mathrm{Km} / \mathrm{h}$ \\
Maximum weight capacity & $6 \mathrm{~kg}$ \\
Motor specification & $12 \mathrm{~V}, \mathrm{DC}$ motor \\
& with high \\
& torque geared \\
& $6 \mathrm{~V}$ Dry cell \\
Battery specification & type battery \\
& with $4.5 \mathrm{Ah}$ \\
Charging time & $8 \mathrm{hours}$ \\
DC adapter & $12 \mathrm{~V} \mathrm{dc}$ \\
PV Panel & \\
Maximum power (W) & $20 \mathrm{~W}$ \\
Optimum power voltage (Vmp) & $17.57 \mathrm{~V}$ \\
Optimum operating current (Imp) & $1.14 \mathrm{~A}$ \\
Open circuit voltage (Voc) & $21.34 \mathrm{~V}$ \\
Short circuit current (Isc) & $1.27 \mathrm{~A}$ \\
Solar cell & $156 \times 23 \mathrm{~mm}$ \\
Type & poly \\
Size & $36 \mathrm{pcs}(2 \times 18)$ \\
Weight & $490 \times 356 \times 20$ \\
\hline
\end{tabular}

and Zener diode ZD act as a cut off switch when the battery is full. Normally T1 is off and battery gets charging current. When the terminal voltage of the battery rises above 6.8 volts, Zener conducts and provides base current to $\mathrm{T} 1$. It then turns on, grounding the output of LM317 to stop charging. The LM317 datasheet specifies that it is an adjustable three-terminal positive-voltage regulator capable of supplying more than $1.5 \mathrm{~A}$ over an output-voltage range of $1.25 \mathrm{~V}$ to $37 \mathrm{~V}$. It is exceptionally easy to use and requires only two external resistors to set the output voltage. Furthermore, both line and load regulation are better than standard fixed regulators.

\section{DPDT switch}

DPDT stands for Double Pole Double Throw relay. They are often used to interface an electronic circuit, which works at a low voltage to an electrical circuit which works at a high voltage. There are two sections : input and output. The input section consists of a coil with two pins which are connected to the ground and the input signal. The output section consists of contactors which connect or disconnect mechanically. The output section consists of six contactors with two sets. Each set has three changeover contacts, namely, normally open 
(NO), normally closed (NC) and common (COM). When no supply is given, the COM is connected to NC. When the operating voltage is applied the relay coil gets energized and the COM changes contact to NO (Shown in Fig 3.).
DPDT switch can be used to power wither one device/appliance or another. DPDT switch can also be used to change the polarity at the terminals of a device connected at output. Here, in order to drive the DC motor in both clockwise and anticlockwise directions, following connections can be done. Pins

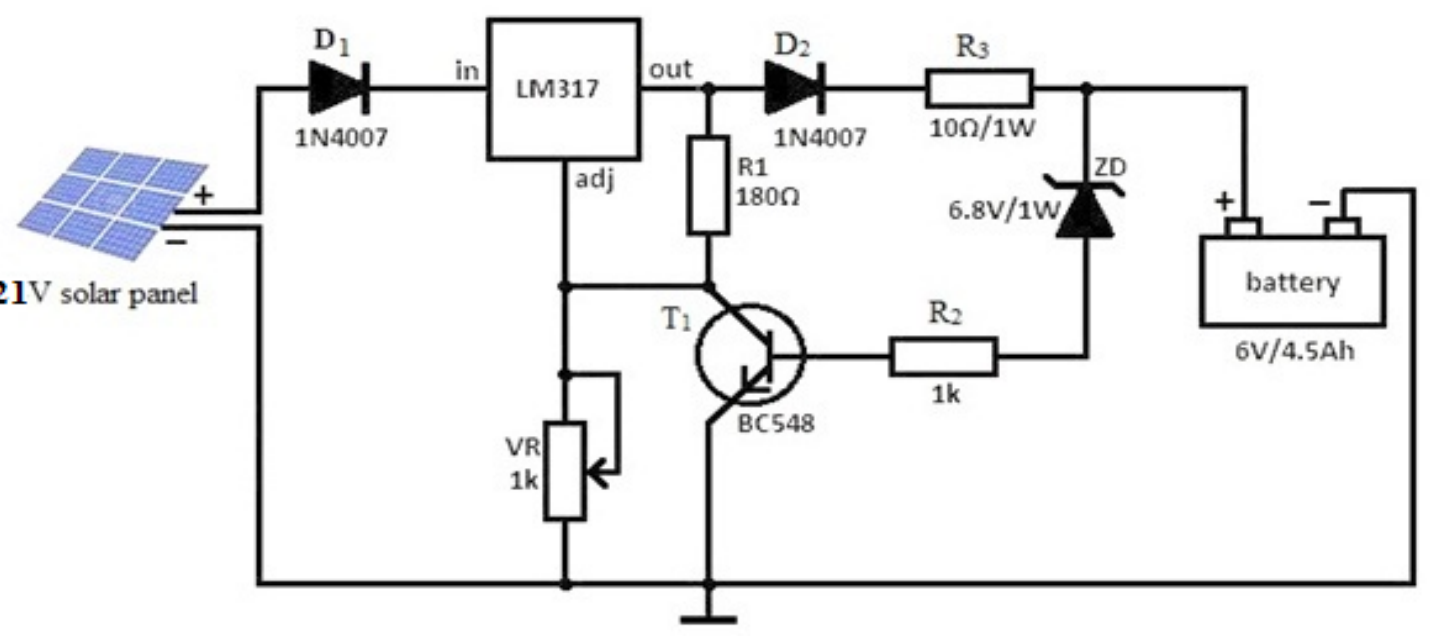

Fig. 2: Charging circuit of PV powered tri-cycle
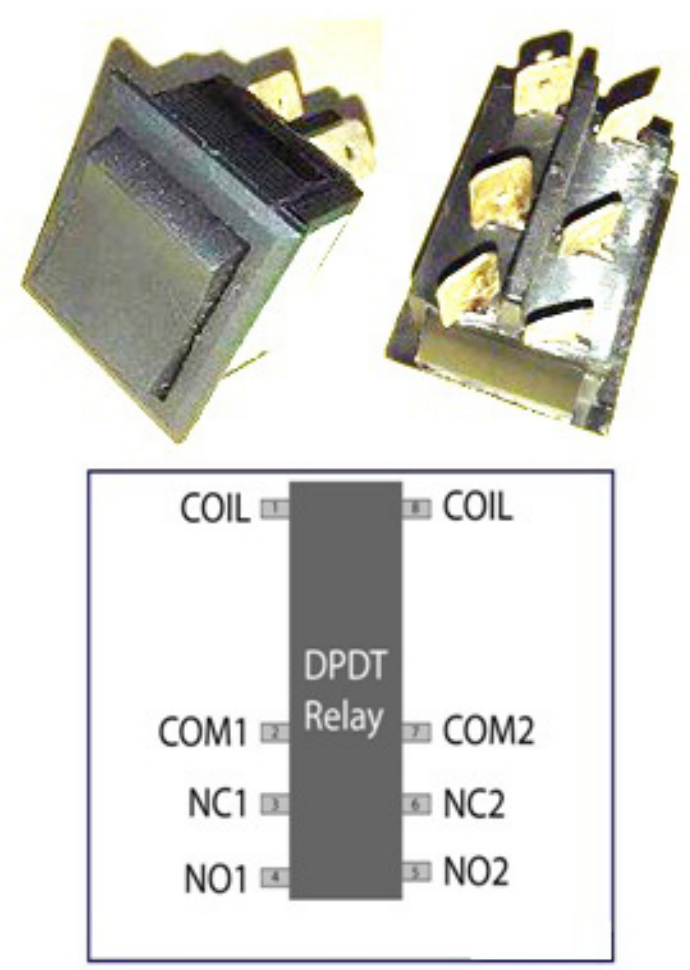

Fig. 3: Schematic of DPDT switch
$2 \& 7$ can be provided with $\mathrm{V}_{\mathrm{cc}}$ ( $9 \mathrm{~V}$ for motor) and ground, respectively. The first motor terminal can be connected to pins $3 \& 4$ while the other terminal to pins $5 \& 6$. In case no input signal is given, the motor would rotate in one direction (say clockwise, depending upon the connection of its terminals). When an input signal is provided, the contactors change their positions, resulting in the anticlockwise rotation of motor.

\section{DISCUSSION}

Since a long year back much awareness has been raised about using solar energy as an alternative to the conventional energy resources like fossil fuels. Many works has been done in this regard before and till now more and more works are in progress. For example, i) the idea of solar power driven vehicles was first initiated in the late 1970 's ${ }^{3}$.In an effort to push forward the making of solar powered automotive technology more viable for manufacturers, ii) solar car racing was instituted first in 1985 called the Tour de Sol and was held in Switzerland. The average speeds attained by the first generation cars were about $60 \mathrm{kmph}$, while 


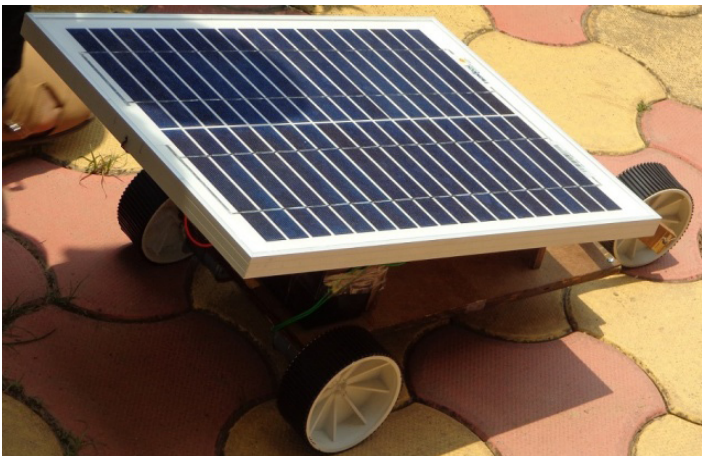

Fig. 4: PV powered Tri-Cycle

the present generations can reach speeds as high as $100 \mathrm{kmph}^{3}$. iii) "Two Seater Solar Car Proposed Prototype" A Project by Sanjana Ahmed, Ahmed HosneZenan, and Mosaddequr Rahman from BRAC University. It is a light-weight car for average $20 \mathrm{kms}$ on a daily basis ${ }^{5}$.iv) "Gato Del Sol"A project by Raghu Mangu, Krishna Prayaga, Bhavananda Nadimpally and Sam Nicaise from University of Kentucky, Lexington. Over 10 years of learning, engineering, and persistence has propelled the University of Kentucky Solar Car Team to the national stage. After securing second place at the 2009 Formula Sun Grand Prix in Cresson, TX, the motivation led the team in 2010 to build Gato Del Sol III, their most efficient solar car till then ${ }^{3}$. v) Students of Qatar University have participated in the latest edition of Shell Eco-marathon competition in the solar car category, held in Germany in May 2011. In this first participation, the aim was to design the first prototype of energy efficient solar and GTL cars to be starter point for a regular participation in future races. The paper4 discussed all the designing steps, components selection, measurements, calculations and manufacturing process that led to the first prototype of the solar car.

So the paper on solar energy driven vehicle is not a new invention. But it will be much more of a choice by means of cost and simplicity. It can be easily understood that controlling the direction of a Tricycle is much easier than a four wheeled car. Also less number of wheels means less drag, less starting friction and more speed wherever necessary. It will also be less costly due to lesser number of wheel and simple control mechanism. So then, for short range journeys, solar powered vehicles can be a great option instead of IC engine cars. This project has great opportunity to be considered commercially acceptable and this kind of Tricycles is to be built to serve the daily needs and purpose of common people. Specifically, the design, assembling and implementation of the parts, maintenance is very easy and cost efficient in case of solar powered Tricycle.

\section{CONCLUSIONS}

A PV powered tri- cycle has been designed and fabricated. A preliminary design of the tri-cycle involving the estimation of the required panel size, battery capacity and motor power has been carried out. The energy demands for office commuting during summer and spring is expected to be met with solar energy alone, while during winter and rainy season, the total energy can be accomplished by supplementation from the main line electricity. With the current rate of inflation in India and the unprecedented growth of fuel prices all around the world, the clean solar car will be beneficial to both the environment and the public who are otherwise exposed to numerous health hazards due to the toxic exhaust gases released from the fuel power cars, thereby threatening the environment. The solar tri- cycle is expected to reduce air pollution, to improve public health and has the potential to reduce the dependency on fossil fuels. Although this solar tri-cycle setup is very small, yet, if it operates for a smaller one, then this principle could be used in bigger one.

\section{REFERENCES}

1. U.K .Mirza, M.M.M.Valer, N.Ahmad. Status and outlook of solar energy use in Pakistan. Renewable and Sustainable Energy Reviews, Pages 501-514. (December 2003).
2. M. Farooq, Adil Salman, Sohaib Ahmad Siddiqui, M. Ibrahim Khalil, and Wasim Mukhtar. Economically Designed Solar Car for Developing Countries (Pakistan). Global 
Humanitarian Technology Conference, IEEE. (2014).

3. R.Mangu, K.Prayaga, B.Nadimpally and S.Nicaise, Design, Development and Optimization of highly efficient solar cars: gato Del sol I-IV. Green Technology Conference, IEEE. pp.1-6. (2010).

4. Nasser Alnunu, Samer Said, Sami AlSharman, Ahmad Al-Ibrahimi, Ahmed AbdulAziz, Mohammed Al Hellabi, Farid Touati, Saud Ghani, El-Sadig Mahdi and Mohieddine Benammar. Design of Qatar University's First Solar Car for Shell EcoMarathon Competition. International Conference on Renewable Energies and Vehicular Technology, IEEE. (2012).

5. Sanjana Ahmed, Ahmed Hosne Zenan, Mosaddequr Rahman. A Two-Seater Light-
Weight Solar Powered Clean Car: Preliminary Design and Economic Analysis. 3rd International Conference on the Developments in Renewable Energy Technology (ICDRET). (2014).

6. Carroll and R. Douglas, The winning solar car: a design guide for solar car teams, $S A E$ International (ISBN, 0768011310). (2003).

7. David Menasce, Michael Grobler, Pieter Janse van Rensburg. High Power Electrical Systems Design for a Solar Car Designing and building the solar car llangal.I. Africon IEEE Conference, Sept. 2013, pp.1-5. (2013).

8. Karden E., Ploumen S., Fricke B., Miller T. and Snyder K; Energystorage devices for future hybrid electric vehicles, journal of power sources, pp 168(2-11),(2007). 